\title{
Comparison of options and optimization of sorting and collection of waste at demolition sites during renovation
}

\author{
Vitaly Chulkov and Ekaterina Yevstigneyeva* \\ Moscow State University of Civil Engineering, 129377, Moscow, Russia
}

\begin{abstract}
The most famous and relevant innovative type of construction reorganization of urban areas is renovation that is defined in the directive documents of the Moscow Government as the demolition and dismantling of buildings in conditionally autonomous urban areas, defined by the wellknown Resolution of the Moscow Government and legal documents explaining it, without taking into account the degree of physical or moral aging of these buildings and structures with the aim of erecting multistorey residential buildings with increased comfort living in these territories. Thus, a certain meaning of renovation makes it possible and necessary to purposefully study and model the life cycle of this sociotechnical and organizational-technological construction process, which has certain formal differences from the well-known model of the traditional life cycle of a construction facility and the sequence of stages in the implementation of this life cycle. The difference in the configuration of the life cycle of a construction facility in the traditional approach and in the innovative one in the conditions of renovation has been determined. In the study, this difference highlights the stage of demolition and dismantling, with which the problem of disposal of construction waste is inextricably linked. In this regard, an urgent task of comparing options and optimization of sorting and collection of waste at demolition and dismantling facilities at the first stage of renovationarises. Three options for solving this problem and projects for the production of work have been developed for each of the three options for the demolition and dismantling of buildings. The most rational is the second option.
\end{abstract}

\section{Introduction}

Reorganization [1, 2, etc.] as a process of restructuring something (buildings or structures, organizational structure or type of activity, socio-technical process, etc.) on new grounds and for achieving new goals and results has long been a fairly well-known topical phenomenon, one of the important characteristics and criterion of the dynamics of the development of social structures.

\footnotetext{
${ }^{*}$ Corresponding author: just.katherin@gmail.com
} 
An infographic model of the basic reorganization cycle, which is a set of interrelated components "Organization, O", "Disorganization, D", "Reorganization, R" and "Coorganization, $\mathbf{C}$ " (fig. 1) is detailed in publications [3, 4, 5, etc.].A particular case of the application of this model is the study of the construction reorganization of residential areas.

In the traditional life cycle of a building object, a variety of distinguishable and interrelated components and characteristics can be considered:

1. Stages and phases of the life cycle, including

Stage one -"Creation or reorganization of a construction facility", in which the following phases can be distinguished: • construction of a new facility ("erection"), • reconstruction of an existing facility ("transformation"); • restoration of a worn-out constructionfacility ("returning it to its normal state");

Stage two -"Operation of a construction facility", in which the phases can be considered repairs of varying degrees of complexity (current, major, in connection with emergencies);

Stage three -"Demolition and dismantling of a construction facility", the phases of which can be considered: - technical inspection to determine the physical and moral deterioration of the structure; - choosing the method of destruction of the construction object ("demolition" or "dismantling"); • handling demolition or dismantling waste; processing (recycling) of waste; • disposal of non-processed waste.

2. Processes and operations of construction production. Each process includes a combination of construction operations that are part of one or more types of construction reorganization. One of the important tasks of the study is the formation of a sample of construction operations for each type.

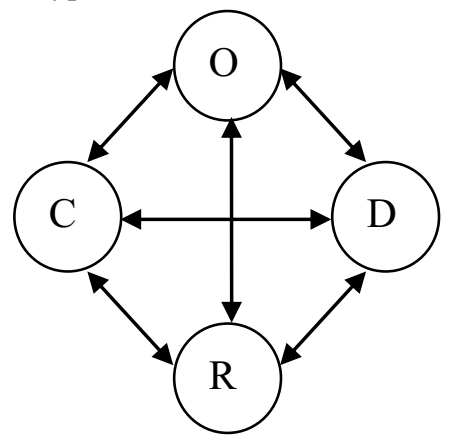

Fig. 1. Infographic model of a basic reorganization cycle (V.O. Chulkov, 1996; R.K. Gazaryan, 2008)

Table 1.

\begin{tabular}{|c|c|c|c|c|c|}
\hline \multicolumn{6}{|c|}{ Components and characteristics of the traditional life cycle of a construction object } \\
\hline \multicolumn{2}{|c|}{ Stages and phases } & \multicolumn{2}{|c|}{$\begin{array}{c}\text { Processes and operations of } \\
\text { construction production }\end{array}$} & \multicolumn{2}{|c|}{$\begin{array}{c}\text { Types of construction } \\
\text { reorganization }\end{array}$} \\
\hline Stages & Phases & Processes & Operations & $\begin{array}{c}\text { Traditiona } \\
1\end{array}$ & Innovative \\
\hline 1 & 2 & 3 & 4 & 5 & 6 \\
\hline $\begin{array}{c}\text { Creation or } \\
\text { reorganization } \\
\text { of a } \\
\text { construction } \\
\text { facility }\end{array}$ & $\begin{array}{c}\text { Reconstructi } \\
\text { on of an } \\
\text { existing } \\
\text { facility } \\
\text { ("transfor- } \\
\text { mation") }\end{array}$ & $\begin{array}{c}\text { Dismant- } \\
\text { ling work }\end{array}$ & $\begin{array}{l}\text { Dismantling of } \\
\text { external walls and } \\
\text { internal walls and } \\
\text { partitions }\end{array}$ & \multirow{2}{*}{$\begin{array}{l}\text { Reconst- } \\
\text { ruction }\end{array}$} & \\
\cline { 3 - 5 } & $\begin{array}{l}\text { Dismantling of } \\
\text { floors, windows, } \\
\text { doors and } \\
\text { finishing elements }\end{array}$ & & \\
\hline
\end{tabular}




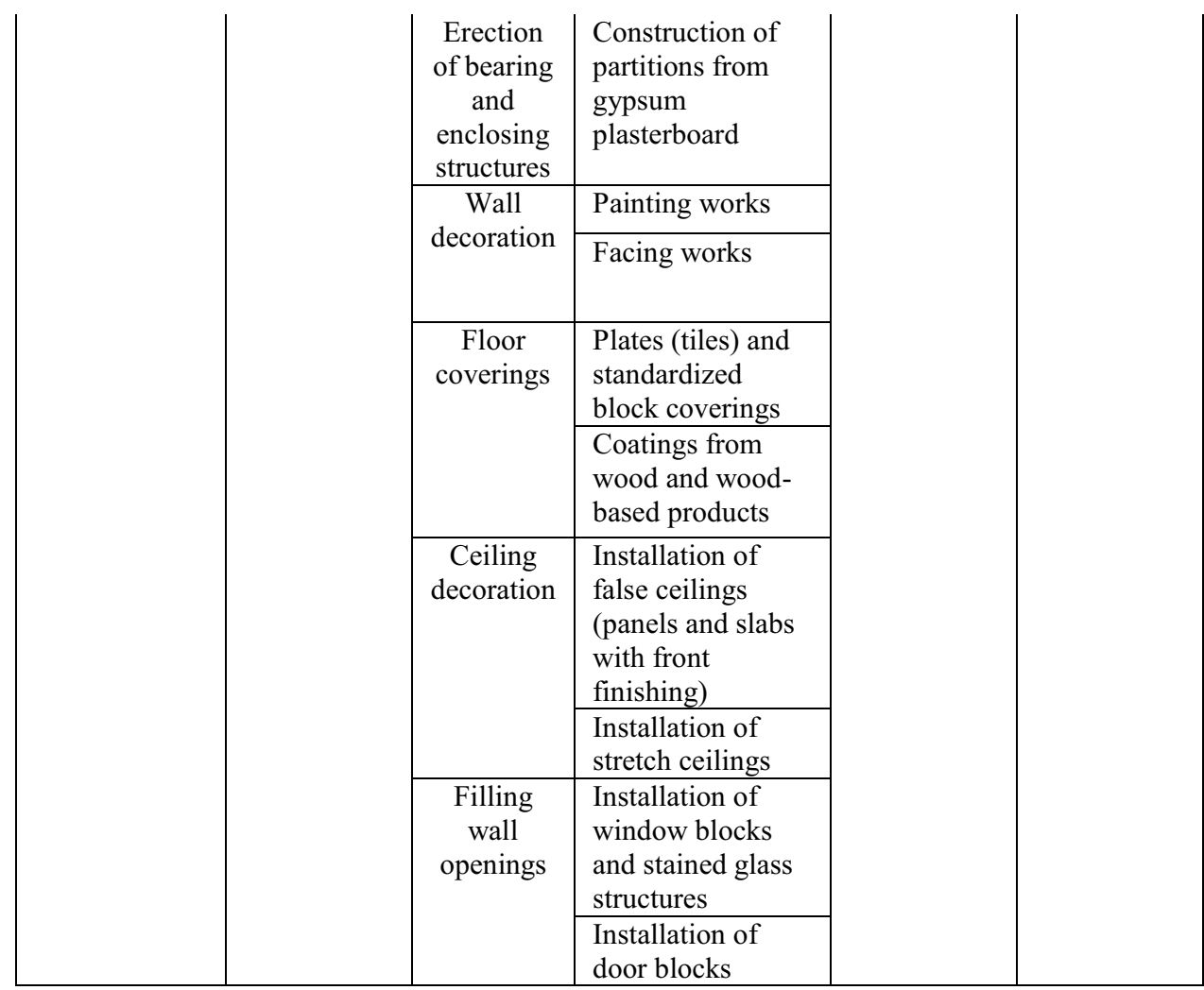

3. Traditional and innovative [6, 7, etc.] types of construction reorganization (Fig.2 [8]).

In conditions when renovation is considered as a shell of innovative types of construction reorganization [8], there are objects that combine several types of construction reorganization in design solutions, for example, retreatment in combination with recomposition or rehabilitation and retreatment. A symbiosis of traditional and innovative types is not excluded, for example: reconstruction in combination with renovation and reequipment. A similar option is also possible within the traditional types of building reorganization: reconstruction with elements of restoration.

As an example, Table 1 shows a variant of the object of the first (out of three) stage of the life cycle - reconstruction (reconstruction object), the second phase - reconstruction of an existing object ("transformation"), type - reconstruction. In full, the table is intended to reflect the dependence of stages, phases, processes and construction operations with the types of construction reorganization in their various combinations and manifestations.

Let's consider the sequence of stages in the construction of a building: after the idea is embodied in the project, the production process begins. The beginning of this process is the erection of a building on an already prepared territory. After the completion of construction, the entry of the object to the construction products market and the its acquisition by the owner, the second stage begins - the operation of the building, during which the object undergoes many repairs, reconstructions and other reorganization processes. The third stage of the life cycle of a construction object is the demolition and dismantling of the building, its destruction. This happens when the reorganization of an object, changing its type or purpose is no longer advisable due to the emergency state of the building or its high physical or moral deterioration. An enlarged structure (sequence of stages) of the traditional life cycle of a construction facility is shown in Fig. 3. 


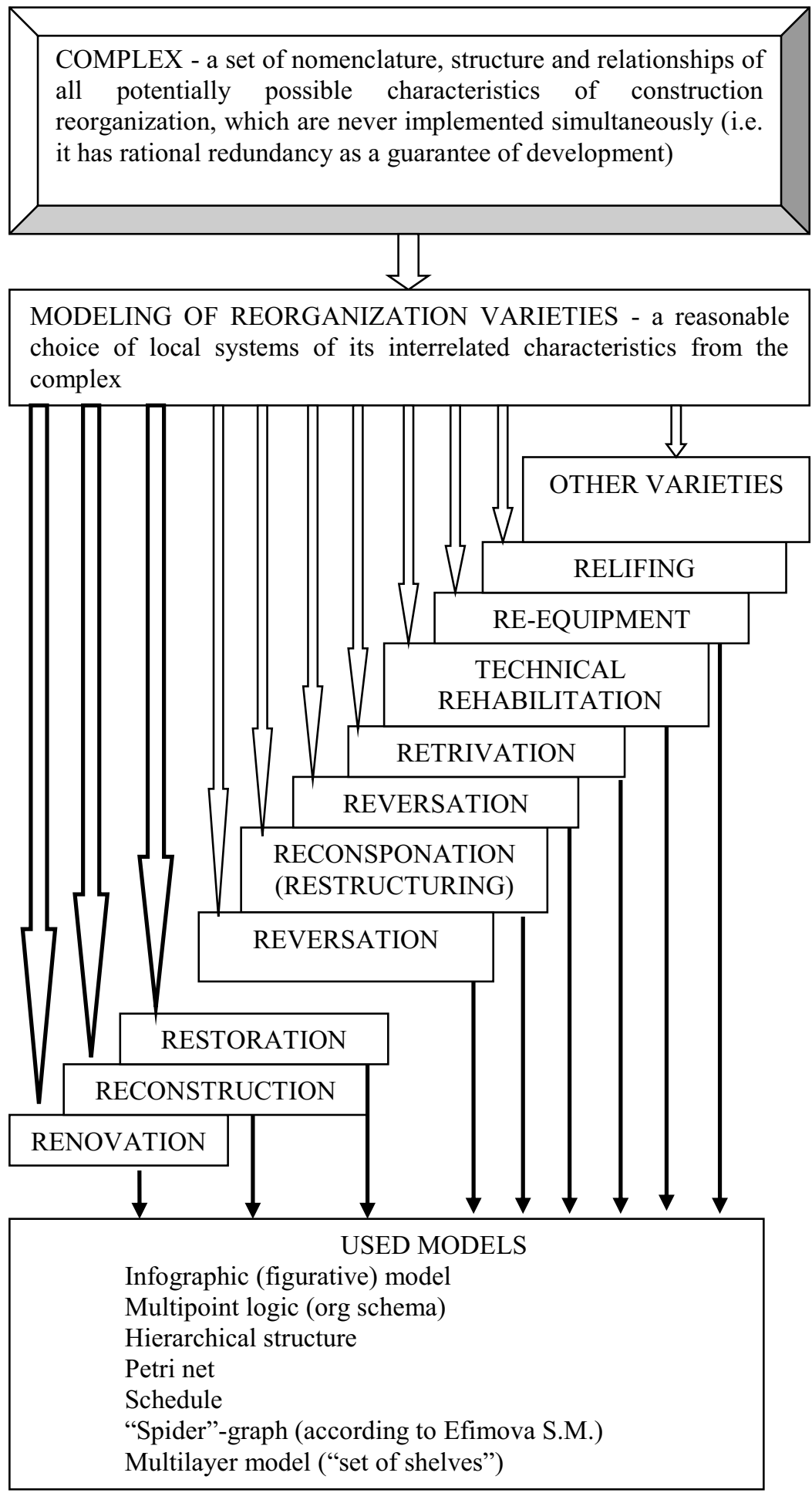

Fig. 2. Traditional (marked with bold outline arrows) and innovative (marked with thin outline arrows) types of construction reorganization (Chulkov V.O., Evstigneeva E.A., 2020 [8]). 


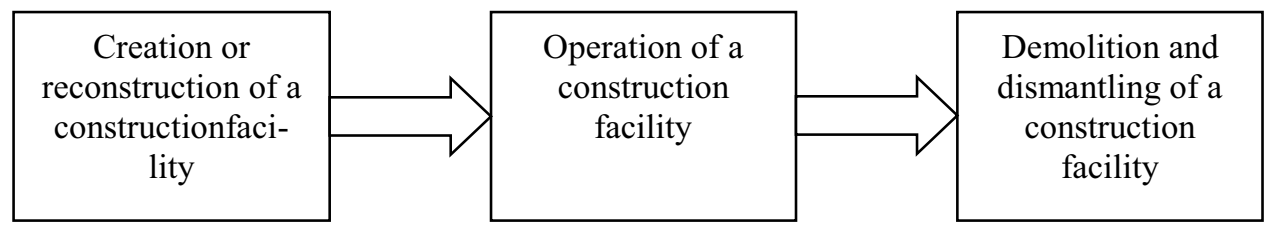

Fig. 3. The enlarged structure (sequence of stages) of the traditional life cycle of a construction facility(Chulkov V.O., 2004 [2]).

\section{Materials and methods}

The structure shown in Fig. 3 can, if necessary, be substantially detailed in relation to a specific construction object (Fig. 4), for which, along with the life cycle, it is also advisable to consider its life path [9].

Certain socio-political intentions of activity (vectors of development and movement along the path of scientific and technological progress) combine the variety of the above structural components and characteristics of the traditional life cycle of a construction facility into functional systems of construction production.

At the same time, new original terms and definitions are found for such socio-political intentions of activity, or they fill existing (most often - in foreign cultures and subcultures)concepts, terms and definitions with new content necessary for researchers(i.e. they correct them).

As a result of the process of adjustment and local change of concepts, known since the end of the 19th century as "hermeneutics" (from ancient Greek $\dot{\varepsilon} \mu \eta \nu \varepsilon \varepsilon v \tau \iota k \dot{\eta}$ " art of interpretation", theory of interpretation) [10], the concept and term "renovation" appeared in Russian construction terminology. In Europe, the term "renovation" has been known since the 18th century and, in its meaning, unites the terms "repair" and "reconstruction". Overseas renovation covers all construction operations related to the restoration of the design values of the object.

Scientific schools of Doctor of Technical Sciences Professor T.G. Maklakova (since 1992) and Doctor of Technical Sciences Professor V.O. Chulkov (since 1996), the Research and Design Center "City Development" and the Moscow Government (since 2017) use the term "renovation" borrowed from European social culture, filling it with a new content that is convenient for them, helping to substantiate scientific and practical development needs [8].

The renovation of the housing stock in Moscow is considered as a set of measures aimed at updating the living environment and creating favorable living conditions for citizens, public space in order to prevent the growth of emergency housing stock in the city of Moscow, to ensure the development of residential areas and their improvement. In contrast to the foreign interpretation, in Russia the renovation has a specific connotation. It is a type of construction reorganization with specific features peculiar only to this type. Renovation has an impact not only in the construction sphere of life, it also affects transport communications, change (improvement) of micro districts with their own infrastructure. So, renovation in Russia is far from the concept of "restoration", as this concept is translated from English. Renovation is now more similar to the concepts of "improvement" and "relocation" (Fig. 5). 


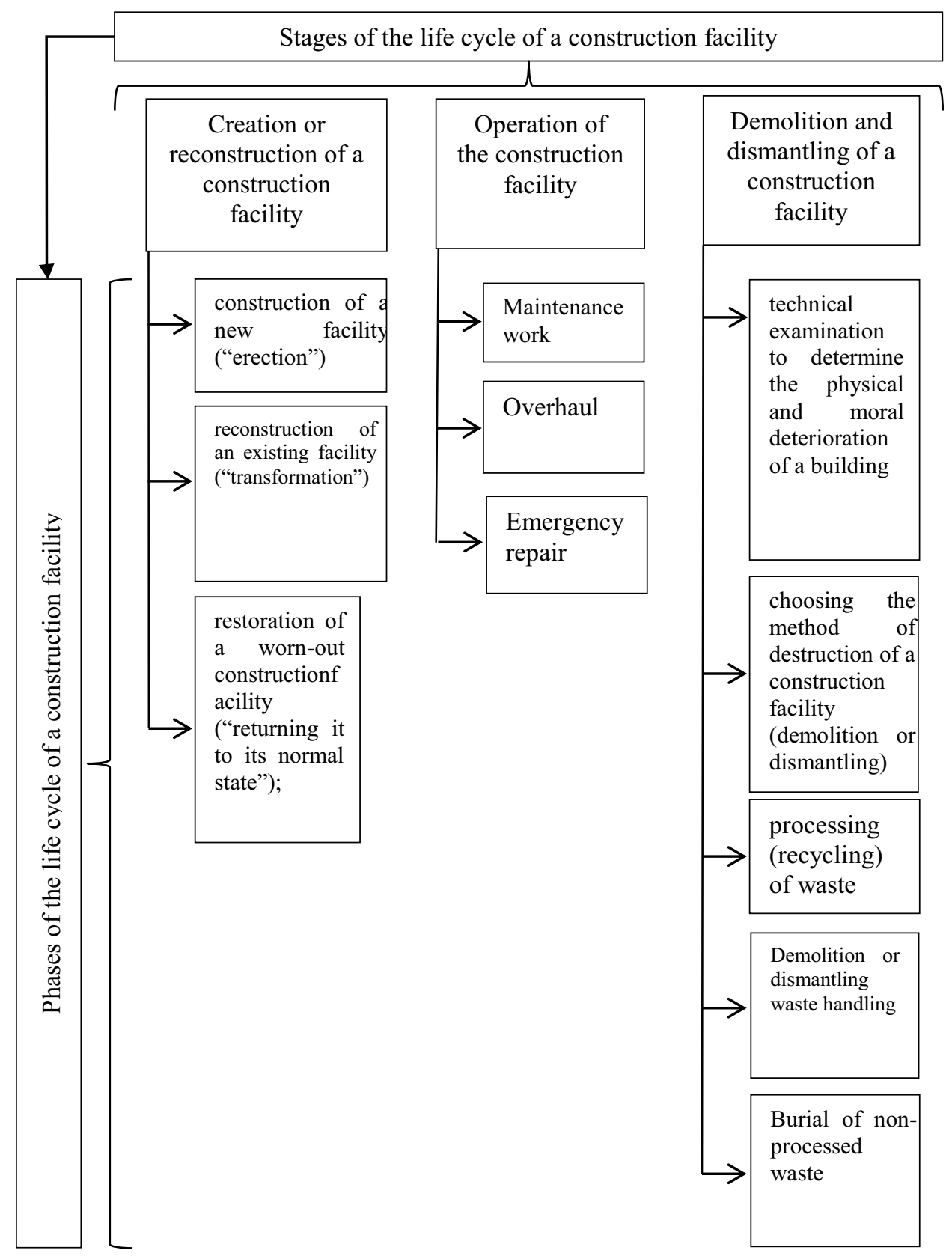

Fig. 4. Detailed enlarged structure (sequence of stages) of the traditional life cycle of a construction facility (Evstigneeva E.A., 2020). 


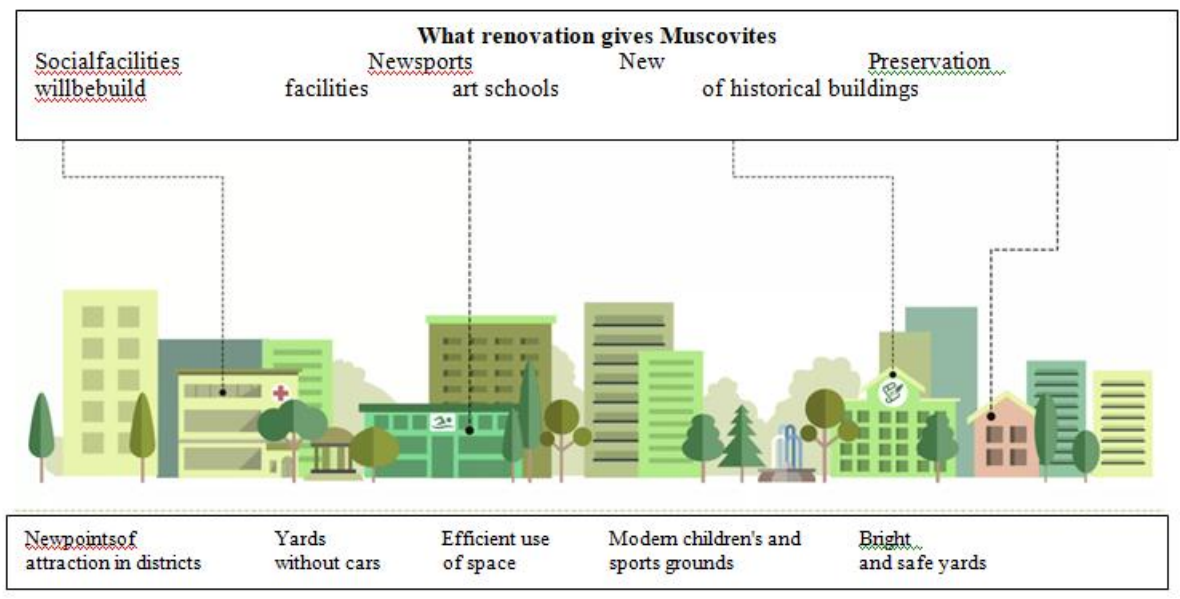

Fig.5. Composition of the renovation program in Moscow (https://www.mos.ru/city/projects/renovation/)

The renovation program was adopted for a period until 2032 and should allow eliminating the imbalance in the development of the urban environment accumulated over the past decades and prevent the massive appearance of emergency housing in the city of Moscow in the next 10-15 years.

In publications $[11,12,13$, etc.], domestic renovation is interpreted as “... the demolition of emergency low-rise buildings and the erection of new modern high-rise buildings in their place that meet all the necessary requirements ...”.

In this regard, we can offer an enlarged structure (sequence of stages) of the renovation life cycle, shown in Fig. 6.

\begin{tabular}{|c|c|c|c|}
\hline $\begin{array}{c}\text { Demolition and } \\
\text { dismantling of a } \\
\text { construction } \\
\text { facility }\end{array}$ & $\begin{array}{c}\text { Creation or } \\
\text { reconstruction of } \\
\text { a construction } \\
\text { facility }\end{array}$ & $\begin{array}{c}\text { Operation of a } \\
\text { construction } \\
\text { facility }\end{array}$ \\
\cline { 2 - 4 }
\end{tabular}

Fig. 6. The enlarged structure (sequence of stages) of the renovation life cycle (Chulkov V.O., Evstigneeva E.A., 2020).

The enlarged structure (sequence of stages) of the traditional life cycle of renovation shown in Fig. 6, within the framework of this innovative type of building reorganization, highlightsthe problem of demolition and dismantling of morally and physically obsolete buildings and structures. This problem for each specific traditional or innovative type of construction reorganization differs in the ratio of the required dismantling and demolition work, and dismantling is always an initial mandatory step.

According to the renovation program, more than 600 buildings should be demolished between 2020 and the end of 2024 [15]. Demolition following dismantling involves the destruction of structures (as opposed to decomposition of buildings, with the possibility of recycling).

The renovation program is accompanied by the problem of burial and disposal of construction waste in an amount equal to demolished dilapidated buildings, road surfaces, public transport stops, etc. One of the tasks within the framework of this problem is to compare options and optimize waste sorting at the demolition site and dismantling of existing buildings and structures during the renovation process. Let's consider one of the options for solving this problem. 


\section{Results}

The study of the state of structures of morally and physically obsolete buildings and constructions showed that the considered structures of wall panels of demolished buildings (in particular, five-story houses of the first series of industrial housing construction) were built from materials of different strength, thermal conductivity and durability. Long-term operation (more than fifty years) of such buildings sharply reduced the strength characteristics of the structural material of the panels, negatively affected the adhesion of the reinforcement to concrete and the adhesion between the layers of sandwich panels [16].

When choosing the option of demolition (destruction, turning a building into a mountain of construction and demolition waste) or element-wise disassembly, sorting and preparation for recycling of elements and components of demolished houses, the following provisions must be taken into account:

- The use of existing slinging loops for lifting panels when dismantling houses without reinforcing the lifted panels or without additional equipment that provides for the capture of panels from the lower edges and simultaneous compression from the sides can lead to an emergency situation with the separation, fall or delamination of the panels.

- It is not permissible to tear off the panels to be dismantled from the fastening cement mortar only with the help of the crane's efforts, without "undercutting" the cement layer and prior complete tear off.

- Dismantling of buildings in sections should only be carried out starting from the roof and floors. When dismantling wall panels, it is also necessary to provide for temporary fastening of the non-dismantled parts of the walls remaining without a common bond stiffness using struts, guy wires, clamps and other technological equipment.

- For the processing of building structures in order to obtain sand and crushed stone mixtures, it is advisable to use only elements of foundations and floor slabs.

Multilayer building envelopes are not suitable for subsequent processing, since during their operation, they were subjected to anthropotechnical and natural pathogenic influences, and during processing, secondary building materials demonstrate very low technical indicators "at the output". That is, with any method of dismantling, part of the building structures remains in the category of construction waste.

The above restrictions significantly increase the cost of dismantling building elements and increase the duration of construction work.

To obtain comparative characteristics of different methods of demolition, a multivariate analysis of the initial indicators was carried out, and three options for the production technology were developed.

Option 1. Mechanical collapse of buildings. The received construction waste is sent for disposal.

Option 2. Carrying out dismantling works on a limited range of dismantled elements with subsequent mechanical collapse of building structures. Sending the received materials for recycling with the further use of secondary materials at construction facilities in the city and/or taking into account the returnable amounts in the consolidated budget calculations.

Option 3. Carrying out a complex of dismantling works, including the internal elements of the building and the supporting structures of the frame, sending the received materials for processing.

To select the best option, work projects were developed for each of the three options for demolition and dismantling of buildings.

\section{Discussion}


In the course of the study, calculations were carried out for labor costs per section of the dismantled building, taking into account the following restrictions:

- demolition and dismantling work must be carried out in two shifts (16 hours);

- such work is performed by a complex team (15 people).

In the process of calculations, the standards developed and published by organizations of the construction industry in Russia were used, shown in Table 2.

Table 2. Specific indicators (per averaged section) for demolition of buildings of II-32 series

\begin{tabular}{|c|c|c|c|c|}
\hline No. & Option name & Developer & $\begin{array}{l}\text { Labor } \\
\text { costs, } \\
\text { person- } \\
\text { days }\end{array}$ & $\begin{array}{c}\text { Term, } \\
\text { days }\end{array}$ \\
\hline 1 & $\begin{array}{l}\text { Mechanical demolition of a building } \\
\text { by a crash }\end{array}$ & $\begin{array}{l}\text { Stroyproekt } \\
\text { JSC }\end{array}$ & 219.6 & 0.9 \\
\hline 2 & $\begin{array}{l}\text { Element-wise disassembly of the } \\
\text { internal elements of the building } \\
\text { (preparatory stage) with the } \\
\text { subsequent demolition of the building } \\
\text { by the crash method }\end{array}$ & $\begin{array}{l}\text { Stroyproekt } \\
\text { JSC }\end{array}$ & 4058.7 & 16.9 \\
\hline 3 & $\begin{array}{l}\text { Element-wise disassembly } \\
\text { (preparatory stage) with the } \\
\text { subsequent dismantling of building } \\
\text { elements }\end{array}$ & $\begin{array}{c}\text { LLC } \\
\text { TsNIOMTP }\end{array}$ & 4876.3 & 20.3 \\
\hline
\end{tabular}

The most preferable option is option 1 (mechanical demolition of a building by a crash), but it does not take into account the requirements to increase the volume of waste processing to obtain secondary materials, reduce the disposal of waste to landfills, as well as the requirement to determine the qualitative composition of the external and internal panels of demolished buildings. Therefore, it was decided to conduct an experiment based on the first two options.

Based on the analysis of the above indicators, the most optimal option is option 2, which provides $[14,17$, etc.]:

- compliance with the current legislation establishing the obligation to send waste for recycling;

- reducing the environmental burden on the environment, including by reducing the "shoulder" of waste transportation;

- possibility of using secondary materials at construction sites instead of natural mineral resources;

- reduction of total costs with separate material accounting of construction and demolition waste due to the reflection in the consolidated estimate calculations of returnable amounts received in the form of payment for the delivery of secondary resources;

- use of existing technologies for processing concrete and reinforced concrete without additional sorting at the processing site;

- reducing dependence on neighboring subjects of the Russian Federation with waste disposal facilities.

When part of the generated waste is delivered to utilization and recycling points located in the city limits, the "shoulder" of waste removal is significantly reduced in comparison with the option of placing them at disposal facilities.

With a comprehensive assessment of the costs of waste management (demolition of buildings, transportation, placement, recycling and reuse), the forecasted cost of work for option 2 is lower than the cost for options 1 and 3 by $102 \%$ and $39 \%$, respectively. 
Limiting the list of dismantled elements and materials, taking into account processing technologies for obtaining secondary materials, allows optimizing the costs of the preparatory stage, excluding the dismantling of vapor barrier and waterproofing, television and electrical cables, dismantling of gypsum partitions and ventilation blocks, and wallpaper removal.

In accordance with option 1, the possibility of reusing panels, floor slabs and foundations is almost completely excluded at housing construction objects of standard series of industrial housing construction.

The third option, which is widely used today, can be used for demolition of buildings in cramped conditions of work, at facilities with small volumes of waste generation and, first of all, with a low content of concrete and reinforced concrete waste.

When buildings collapse without a preparatory stage, labor costs for demolishing the building are lower compared to the other two options, which subsequently increases the cost of transportation and disposal, the use of natural mineral resources with the possible use of secondary resources.

Taking into account the analysis of all factors, the most rational option is option 2.

\section{Conclusions}

The study showed that the traditional life cycle of a construction facility and the life cycle of a renovation differ in a sequence of stages and phases, which forces the prioritization of known stages in a new way.

The identification of new innovative varieties of building reorganization allows adjusting the use of these varieties at all stages of the life cycle.

The main initial stage of renovation is the demolition or dismantling of morally or physically worn-out buildings, the study of which is the subject of this paper.

The problem of utilization of construction waste during the implementation of the renovation program has been identified.

Comparing options and optimizing waste sorting at demolition and dismantling sites is an important renovation task.

The most rational option of the production technology of the "demolition and dismantling" stage has been selected - option 2 .

\section{References}

1. P.P. Oleynik, Organization, planning and management in construction: Textbook (ASV, Moscow, 2015).

2. V.O. Chulkov, Reorganization. Organizational and anthropotechnical reliability of construction. Series "Infographic foundations of functional systems (IFFS)" (SvRARGUS, Moscow, 2005).

3. A.I. Prigozhin, Disorganization. Reasons. Kinds. Overcoming (Alpina Business Books, Moscow, 2007).

4. V.O. Chulkov, R.K. Gazaryan etc., Interaction of models of the organizational life cycle of enterprises and their reorganization (Vestnikof MGSU, Moscow,) 3 223-227 (2020).

5. V.O. Chulkov, O.N. Kuzina, Functional modeling of construction reorganization of non-production facilities, Vestnik of MGSU, Series "Information systems and logistics in construction" 9, 251-258 (2012). 
6. D.G. Fedotenkov, A.A. Padalko, Investment and innovation potential as the basis for the development of the regional economy, Young Scientist 3, 565-572 (2014). Information on https://moluch.ru/archive/62/9325/ (date of access: 05.09. 2020).

7. M.O. Karpenko, Modern approaches to the concept and classification of innovations, Vestnik of BSU 3 129-132 (2013).

8. E.A. Evstegneeva, V.O. Chulkov, Renovation as a shell of many innovative types of reorganization in the life cycle management of construction objects, The Eurasian Scientific Journal, 2 (2020). Information on https://esj.today/PDF/68SAVN220.pdf (open access). Title from the screen. Russian, English languages. DOI:10.15862/68SAVN220

9. V.O. Chulkov, Monitoring of the Dynamics of Changes of the Human Adaptive Norm in Cyberphysical Sestems of "Smart Buildings" Using Digitalization, $2^{\text {nd }}$ International Scientific and Practical Conference "Modern Management Trends and the Digital Economy: from Regional Development to Global Economic Growth (MTDE 2020). Advances in Economic, Business and Management Research, Atlantis Press 138 (2020).

10. Hermeneutics. Information on https://ru.wikipedia.org/wikiDate of access 3.9.20

11. Resolution of the Moscow Government dated August 1, N 497-PP "On the Program for the renovation of the housing stock in the city of Moscow" (2017).

12. Renovation. Large-scale urban project of dispersed construction (Moscow, Russian school, 2018).

13. Laws on renovation - essence, provisions and recent changes. Information on http://renovatsija.ru/zakon-o-renovatsii/ Date of access 3.8.20

14. B.V. Gusev, A.A. Kalgin, V.O. Chulkov, I.I. Pavlinova, M.A. Fakhratov, Resourcesaving technologies and ecology (Russian school, Moscow, 2020).

15. Order of the Moscow Government dated August 12, 2020 No. 45/182 / PR-335/20 "On the stages of implementation of the Program for the renovation of the housing stock in the city of Moscow"

16. B.V. Gusev, A.A. Kalgin, A.A. Kalgina, V.O. Chulkov, Operation and repair of residential buildings (Mask, Moscow, 2020).

17. A.A. Kalgin, I.I. Pavlinova, Ecological safety of citie (MGAKHiS, Moscow, 2009). 